\title{
The Procedure for Collecting Medicinal Plants, Basic Tools and Technology for Preparing Medicinal Forms from their Raw Materials
}

\author{
Salimova Noila* \\ Institute of Veterinary Medicine, Uzbekistan \\ *Corresponding author: Salimova Noila, Student of the Samarkand, Institute of Veterinary Medicine, Uzbekistan
}

\section{ARTICLE INFO}

Received: 稳 July 23, 2020

Published: August 12, 2020

Citation: Salimova Noila. The Procedure for Collecting Medicinal Plants, Basic Tools and Technology for Preparing Medicinal Forms from their Raw Materials. Biomed J Sci \& Tech Res 29(3)-2020. BJSTR. MS.ID.004812.
ABSTRACT

The article contains information on the procedure for harvesting the raw materials of medicinal plants, the main active substances contained in them, as well as the technology of preparation of various forms of drugs.

Keywords: Carbohydrates; Alkaloid; Saponin; Vitamin; Phytoncide; Ethereum; Glycoside; Mineral Salts; Neurotropic; Gonadotropic; Infusion; Broth

\section{Introduction}

Currently, the use of medicinal drugs and their application in medical and veterinary practice is widely introduced. Because the fact that several artificial drugs, which have been used for the next 10-15 years, show their negative effects on the body, is emphasized by specialists. Medicinal herbs retain many biologically active substances, as well as macro and microelements, which are natural in their composition. More than $30 \%$ of these plants can be used as medicinal substances [1]. Among the components in which there is a medicinal property of medicinal plants, it is harvested as a raw material. It is obtained from the buds of some plants (White Poplar, White Birch, currant), bark (fodder, dogwood, mulberry), leaves, flowers, seed fruits (cumin, acorpion, sandalwood, cornflower, lilac, strawberry, poppy), roots (ginseng, gooseberry, willow). The shoots are very gently harvested during the winter, early spring. And the bark is separated from healthy branches, where the plants are two years old, during which frosts begin to flow. The leaves are harvested when the plant has turned yellow. The resulting leaves must necessarily be healthy. Flowers are harvested at the end of the budding period, when it no longer begins to open. The collected flowers are dried in baskets and rooms, that is, in shady places. Fruits and seeds can be harvested several times, depending on the ripening. Roots are dug out during the winter hibernation of plants, washed in running water and dried in special drying areas. In pharmaceutical plants, there are special rooms and equipment for drying medicinal plant raw materials [2].

For the restoration, reproduction and protection of medicinal herbs, the following rules are required:

a) Good knowledge of all the characters and characteristics of plants;

b) Do not disassemble the plants, do not tear them with a stem or a STEM, as well as endings;

c) If you are preparing to collect the roots or onions of plants, collect them all without digging, but leaving in the middle;

d) Do not collect seeds in the period of milk ripening (in raw form), fruit without ripening;

e) Not picking up all the fruits in the laid seedham;

f) Do not collect all the flowering or fertilized plants (it is mandatory to leave 30-40 percent of them);

g) To replace the fields to be harvested every two to five years; 
h) Avoid sweating of infected and infected plants (taking measures against them);

i) To organize reserves for the purpose of storing rare plants and not to feed livestock on them, as well as not to harvest them as fodder.

In the preparation of medicines from vegetable homeopaths, proteins, fats, carbohydrates, alkaloids, efir oils, saponins, flavonoids and other biologically active substances with pharmacological value play an important role [2].Proteins are the most necessary substances for a living organism, and all biochemical processes occurring in the body occur either through the protein or with its direct participation. The process of protein formation from chemical compounds can occur only through the world of plants. Proteins are simple and complex. Simple protein-protein consists mainly of amino acids. Complex proteins, in addition to amino acids, contain nucleic and phosphate acids, carbohydrates, fats and other substances.

Fats serve as a reserve substance, which gives the body mainly energy. Also, fats are one of the components of the tissue of a living organism. Fats are composed of the sum of complex organic substances obtained from plants and animals. The main part of this mixture is formed by complex esters of glycerides - glycerin btlan fatty acids. Fats accumulate mainly in the fruits, seeds of plants, and in animals-in the subcutaneous tissues, as well as around the internal organs. In the cell of the plant, the oils are always in a liquid state. One of the properties of vegetable oils is the presence in their composition of mineral compounds, phosphatides. Phosphatides are part of the cell membrane and have the property of permeability. Carbohydrates are also of great importance for the vital activity of a living organism. Carbohydrates are found mainly in products obtained from plants, and in very small quantities in animal products. Carbohydrates in products from plants are threaded in the form of sugar, glucose, starch, kletchatka. When consumed more than the norm of carbohydrates, it has a negative effect on several properties of the body. This leads to a violation of fat metabolism with protein and increases the need for vitamin V1.

Alkaloids are substances made up of highly complex organic compounds that have a nitrogen-preserving and alkaline property that accumulates in plants. These substances have a specific physiological affective property. Alkaloids are used in the production of various drugs, such as morphine, papaverine, quinine, caffeine, codeine. Efir oils consist of complex compounds of several substances that accumulate in all parts of plants, are genetically intertwined, are a collection of organic substances that have the property of being volatile. Components of Efir oils include hydrocarbon, alcohol, aldehyde, ketone, phenol, lactone, efir, henna, acid, nitrogen compounds and many other substances. So far, more than 1000 components of efir oils have been identified. It is found that the composition of the essential oil from Mint contains about 107, in geranium about 270 additives. Efir oils are found in the leaves of mint, basil, coriander, lemongrass, sherolgin, lemon Wormwood, eucalyptus, Laurel and many other plants, in the flowers of roses, daffodils, pearls, marjoram, Jasmine, Poplar, Birch buds, fennel, cumin, wild carrots, seeds of bitter almonds, in the fruit peel of lemons and mandarins, and is, in the flower of gulsapsar it accumulates in the root [2].

Saponins are found in all parts of plants, the amount and quality of which varies depending on the periods of development of plants. Near the development of plants, the amount of saponin in the STEM and nodes increases. Saponins have the property of multiplying, belong to the group of glycosides. Drugs made from saponins are used in medicine as a expectorant, diuretic agent in sputum. Flavonoids are composed of heterocyclic compounds of organic substances, which are found in plants, mainly in the case of pigment threeraydi. Sometimes glycosides are in the form of glucose, ramnose, galactose and other sugar substances. They have a spasmolytic and expectorant effect, as well as great benefits in the treatment of inflammation and duodenum injuries. Some phlavonoids-rutin and quercetins have the property of strengthening capillary vessels as well as intensifying the walls of blood vessels [2].

Glycosides are one of the substances that accumulate most often in plants, have a rather complex structure. According to its chemical structure, cardiac glycosides are complex compounds that retain nitrogen, consisting of two parts: sugar (glycol) and sugar-free (aglicon). The undigested part has a steroid structure associated with an unsaturated lactone ring. The biological effect of cardiac glycosides depends on the part without it. And the sugar part ensures that the heart glycosides are absorbed, passed through the membranes and held in tissues. Glycosides are the most basic and widely used substances in the treatment of cardiovascular insufficiency. Cardiac glycosides are complex organic substances that affect the heart, which are obtained from plants. Taking pure glycosides from plants that grow in Central Asia, academician N.K. Abubakirov, the first Doctor of Science in the field of Pharmacology from Uzbek women in Pharmacological examination of cardiac glycosides, their application to practice, Professor S.S. Azizova's hisses are large. Cardiac glycosides are derived from several types of digitalis (Digitalis purpurae, digitalis lanata), Adonis (Adonis vernalis), marvalidgul (Corvallaria majalis), chitran (Erysimum canensens), strofant (Strophanthus Combe), oleandr (Nerium oleandr), hemp (Apocinum cannabinum) and other plants. At present, many plants have been identified that protect cardiac glycosides. Among them, the main ones are: several types of angishvonagul, Pearl, Willow grass, strofant, sambitgul, chitrangi (Celtic), camomile flower, cannabis hemp.

One of the invaluable properties of cardiac glycosides is that they affect the diseased heart, revitalizing its attenuated activity [3]. Mineral salts actively participate in the normalization of the work of biochemical processes and systems that take place in the body. Mineral substances (iron, copper, cobalt, manganese, nickel) are important in the creation of blood, as well as in the formation and restoration of tissues of the body. Especially in the formation 
of bone tissue, phosphorus and kaltsium are the main agents. Vitamins are the most necessary constituents of vitamins for the vital activity of the body. Currently, more than 30 types of vitamins have been studied in medical practice, of which about 20 are actively involved in the metabolism of the body. Vitamins are divided into two groups; their water soluble and fat-soluble types are distinguished. Water soluble vitamins C, V1, V2, B6, RR, V12, fat soluble vitamins A, D, E, K group vitamins. Phytoncides are one of the biologically active substances inherent in the world of plants. Phytoncides that separate from plants (in Greek phytonutrients - plant, which in Latin means tsido - kill) kill bacteria, fungi, or have a negative effect on their development. Famous scientist P. P. Tokin was the first to discover these properties that would be present in plants in 1982 year. Phytoncides are considered one of the factors that make up the natural immune system in plants, and it neutralizes itself with this substance, which is formed in the process of life. Phytoncides, characteristic of plant specimens, are composed of phenols, zionogen, glycosides, terpenoids, excipients, alkaloids, lactones, organic acids, sulfur compounds [2].

Hawthorn-Crateagus. Hawthorn fruit and Rose are used in the prevention and treatment of cardiovascular diseases, as well as Asab as a soothing and lowering blood pressure. Hawthorn belongs to the family of Raccoon (Rosaceae), a tree up to $5 \mathrm{~m}$ in height, it is distributed mainly in the mountainous regions of our republic. Several types of Hawthorn in Uzbekistan are threeraydi, especially yellow Hawthorn (Crateagus pontica L.) widely distributed, the fruit is consumed. And in medicine it can use hawthorn fruit and flowers of 6 species. Mainly widely used is the red Hawthorn-that is, the Turkistan Hawthorn (Crateagusturkestanica). The leaves, flowers and fruits of this tree are curative. Hawthorn is called "gratas" (strong) in Latin. Fruits contain up to 20 percent sugar, 8 percent fat, and substances such as flavonoids, choline, acetylcholine, additives, carotene, vitamin C, organic acids. In some species of Hawthorn, which grows in the conditions of Uzbekistan, vitamins V1, V2, RR, S, E are found.

Note: Hawthorn should not be consumed on an empty stomach. Because it squeezes the intestine and causes vomiting. After eating the fruit cannot drink cold water over it. Do not forget that otherwise it will cause a stab in the stomach. Also, excessive consumption of it is harmful to the kidneys. Again, it weakens the stomach, causing colic, nausea and vomiting. Treatment of the fruit with decoction, tincture, ointment and medicines made from it should be applied only on the advice of a doctor and under his supervision. In medicine, Hawthorn is brewed using berries, leaves, branches and flowers. It is also used in the prevention and treatment of cardiovascular diseases, as well as a drug that calms the heart, lowers blood pressure [2].

\section{Eman Coat-Cortex Quercus}

The reeds-belonging to the family of Fagaceae, wild and culturally grown Brown fodder-Quusus report L. and the busy floral
eman-Quercus petraea (Mattuschka) Liebl. fresh branches of their trees harvested in early spring, young branches and bark of thin shrubs. In the pharmacological property, in the main substances of the composition (at least $8 \%$ ) there is a property of astringent action [4]. This is the technology of preparation of tincture and decoction of medicinal forms from chamomile of medicinal herbs.

a. The preparation of tincture (Infusum) is aimed at removing the medicinal substances contained in the plant chamomile with the help of water. Tincture is prepared mainly from thin parts of medicinal plants, namely leaves, herbs and flowers. For the preparation of tincture and decoction, a special infundur apparatus is used. The main effect of the medicinal plant chamomile, which is taken for the preparation of tincture and decoction, is required to take in different proportions, depending on the properties of the active substance. If the vegetable homashy from which the boil is prepared is obtained from poisonous plants, then 1:400 should be taken in the proportion of 1:30 and other harmless plants from plants, the composition of which retains a strong acting substance. For example: for the preparation of tincture from hawthorn fruit take $15 \mathrm{~g}$ of fruit and $150 \mathrm{ml}$ of boiling water. Initially, the fruit is put in a container of infundur, on top of which $150 \mathrm{ml}$ of boiling water is added, and the lid of the container is closed and put on a boiling water bath for 15 minutes. Then the mixture is cooled to 18-20 • sharorat, for 45 minutes. After that, it is filtered and added boiling water until it reaches full $150 \mathrm{ml}$ on the resulting tincture. Prepared such a tincture is recommended in hypertension, liver diseases, as well as a soothing agent. The shelf life is 2-4 days.

b. Decoction (ococtum) preparation is also aimed at separating the main means contained in plants with the help of water, and as a raw material, the medicinal plant is prepared from the hard parts, mainly from the roots, bark, stem, branches, seeds and fruits. For example: for the preparation of a decoction from a decoction of oak bark, a decoction of $20 \mathrm{~g}$ of oak bark is put in a container of infun (glaze) and pour $200 \mathrm{ml}$ of warm water on it. The mixture is boiled for 30 minutes, then it is cooled for 10 minutes. In the dock, it is filtered into a separate container, on which boiling is added until the volume reaches $200 \mathrm{ml}$. Decoction of oak bark has astringent and antiseptic properties, is recommended for stomatitis, loringitis, gastritis, enteritis, inflammation of the colic and urinary tract, purulent wounds, gynecological diseases. The shelf life is 2-4 days.

\section{Conclusion}

Taking into account the fact that special attention is paid to the development of the preparation of natural medicines on the basis of protection, cultivation and processing of medicinal plants belonging to the local flora of Uzbekistan, we believe that the procedure for harvesting medicinal plants, the main tools and all the rules required for the implementation of the technology of preparation of.

\section{References}

1. E Negmatov (2012) Treatment with medicinal herbs. Monographs. Samarkand. 
2. Usmankhodzhaev (2018) Etymological modern Encyclopedia of medicinal plants growing in Uzbekistan. Generation of the new century. Tashkent.

ISSN: 2574-1241

DOI: $10.26717 / B J S T R .2020 .29 .004812$

Salimova Noila. Biomed J Sci \& Tech Res

(c) (i) This work is licensed under Creative

Submission Link: https://biomedres.us/submit-manuscript.php
3. Yu Salimov (2019) Veterinary pharmacology. Publisher.

4. HH Kholmatov, OA Ahmedov (2008) Pharmacognosy. Publishing house named after chulpon-printing creative house. Tashkent.

\begin{tabular}{ll} 
BIOMEDICAL & Assets of Publishing with us \\
RESEARCHES & - Global archiving of articles \\
& - Immediate, unrestricted online access \\
\hline ISSN: $2574-1241$ & - Rigorous Peer Review Process \\
&
\end{tabular}

